2005s-35

\title{
The Measure and Regulation of Competition in Telecommunications Markets
}

Marcel Boyer

Série Scientifique
Scientific Series

Montréal

Novembre 2005

(C) 2005 Marcel Boyer. Tous droits réservés. All rights reserved. Reproduction partielle permise avec citation du document source, incluant la notice (C).

Short sections may be quoted without explicit permission, if full credit, including $\mathbb{C}$ notice, is given to the source.
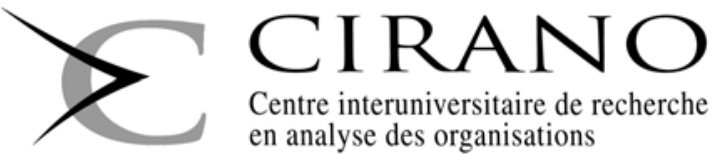

Centre interuniversitaire de recherche en analyse des organisations 


\section{CIRANO}

Le CIRANO est un organisme sans but lucratif constitué en vertu de la Loi des compagnies du Québec. Le financement de son infrastructure et de ses activités de recherche provient des cotisations de ses organisations-membres, d'une subvention d'infrastructure du Ministère du Développement économique et régional et de la Recherche, de même que des subventions et mandats obtenus par ses équipes de recherche.

CIRANO is a private non-profit organization incorporated under the Québec Companies Act. Its infrastructure and research activities are funded through fees paid by member organizations, an infrastructure grant from the Ministère du Développement économique et régional et de la Recherche, and grants and research mandates obtained by its research teams.

PARTENAIRE MAJEUR

\section{Les organisations-partenaires / The Partner Organizations}

. Ministère du Développement économique, de l'Innovation et de l'Exportation

PARTENAIRES

. Alcan inc.

. Banque du Canada

. Banque Laurentienne du Canada

. Banque Nationale du Canada

. Banque Royale du Canada

. Bell Canada

. BMO Groupe financier

. Bombardier

. Bourse de Montréal

. Caisse de dépôt et placement du Québec

. Fédération des caisses Desjardins du Québec

- GazMétro

. Hydro-Québec

. Industrie Canada

. Ministère des Finances du Québec

. Pratt \& Whitney Canada

. Raymond Chabot Grant Thornton

. Ville de Montréal

. École Polytechnique de Montréal

. HEC Montréal

. Université Concordia

. Université de Montréal

. Université du Québec

. Université du Québec à Montréal

. Université Laval

. Université McGill

. Université de Sherbrooke

AssociÉ À :

. Institut de Finance Mathématique de Montréal (IFM²)

. Laboratoires universitaires Bell Canada

. Réseau de calcul et de modélisation mathématique $\left[\mathrm{RCM}^{2}\right]$

. Réseau de centres d'excellence MITACS (Les mathématiques des technologies de l'information et des systèmes complexes)

Les cahiers de la série scientifique (CS) visent à rendre accessibles des résultats de recherche effectuée au CIRANO afin de susciter échanges et commentaires. Ces cahiers sont écrits dans le style des publications scientifiques. Les idées et les opinions émises sont sous l'unique responsabilité des auteurs et ne représentent pas nécessairement les positions du CIRANO ou de ses partenaires.

This paper presents research carried out at CIRANO and aims at encouraging discussion and comment. The observations and viewpoints expressed are the sole responsibility of the authors. They do not necessarily represent positions of CIRANO or its partners. 


\title{
The Measure and Regulation of Competition in Telecommunications Markets
}

\author{
Marcel Boyer*
}

\begin{abstract}
Résumé / Abstract
Le développement du réseau canadien des télécommunications est influencé de façon significative par le cadre réglementaire adopté pour régir l'évolution de ce réseau vers la concurrence. Cet article a deux objectifs principaux : d'une part, développer un cadre méthodologique adéquat pour caractériser le niveau de concurrence dans l'industrie des télécommunications, plus particulièrement du marché des services résidentiels locaux, et, d'autre part, de proposer des changements (importants) au cadre réglementaire actuel. Je montre que le cadre réglementaire actuel peut engendrer des problèmes importants pour les consommateurs et l'industrie ainsi que des pertes d'efficacité pour l'économie canadienne. Il existe un besoin urgent de réformer le cadre réglementaire actuel, en mettant l'accent sur trois rôles essentiels de l'agence de régulation des télécommunications comme fournisseur d'informations aux consommateurs, comme gestionnaire des conditions de concurrence loyale pour toutes les entreprises et comme promoteur de programmes d'investissement efficaces.
\end{abstract}

Mots clés : concurrence, réforme de la réglementation, télécommunication

The development of the canadian telecommunications web is significantly influenced by the regulatory framework put in place to oversee the evolution of the web toward a competitive system. This paper has two specific objectives: first, to develop a methodological framework, which will allow a proper characterization of the level of competition in the telecommunications industry, more specifically in the residential local access market and second, to recommend some (significant) changes in the CRTC approach to the regulation of the Canadian Telecommunications industry. I argue that the current approach to the regulation of telecommunications in Canada is likely to generate significant harms to consumers and businesses as well as efficiency losses for the Canadian economy. I conclude that there is a urgent need for a telecommunications regulatory reform, with a stronger accent put on three crucial roles of the telecommunications regulator as the trusted generator of information for the consumers, as the manager of the level playing field conditions, and as the promoter of efficient investment programmes.

Keywords: competition, regulatory reform, telecommunications

\footnotetext{
* Bell Canada Professor of Industrial Economics, Université de Montréal, C.D. Howe Scholar in Economic Policy, Fellow, CIRANO and CIREQ. Address: CIRANO, 2020 rue University, 25étage, Montréal (Québec), H3A 2A5; e-mail: marcel.boyer@cirano.qc.ca
} 


\section{EXECUTIVE SUMMARY}

Telecommunications and more generally information and communication technologies (ICT) constitute the backbone of our societies. Nothing is more important for the well being, present and future, of Canadians than getting an efficient web of telecommunications chains and networks. Such a web is essential for social cohesion, productivity gains, innovation and commercialization, and for reaching the highest level of humanist economic growth.

The development of the Canadian telecommunications web is significantly influenced by the regulatory framework put in place to oversee the evolution of this web towards a competitive system through policies aimed to protect newcomers from aggressive incumbents and to protect the public against the capacity of large firms to exercise their market power through either inflated prices or reduced quality, diversity and quantity of telecommunications services, or both. If and when the level of competition is deemed sufficient, specific economic regulation will disappear in favour of general competition or antitrust policy while technical, architectural or design regulation and coordination will subsist. Is the current level of competition in the Canadian telecommunications industry sufficient and if not, when will it be, that is, what value of which indicators will tell us that the time has come? The answers to those questions is vital for Canadian society since too much economic regulation for too long generates important social costs in terms of price manipulation leading to losses in consumer welfare, productivity, innovation, and growth. Similarly, too little economic regulation for too short a time generates important social costs in terms of price manipulation leading to losses in consumer welfare, productivity, innovation, and growth. Both generates similar costs because both lead to a plethora of improper prices and price cascades, that is, prices that do not emerge from a competitive environment and do not constitute a competitive equilibrium between demand and supply, that is, an efficient balance between the interest of consumers/customers and sellers/producers.

The two specific objectives of this paper are first to develop a methodological framework, which will allow a proper characterization of the level of competition in the telecommunications industry, more specifically in the residential local access market, and 
second to recommend some (significant) changes in the CRTC approach to the regulation of the Canadian Telecommunications industry. It addresses major concerns of the regulators regarding two "factual measurements," first the small number of competitors in the residential local access and second the high market shares captured by the incumbent firms, even after a decade of favourable policies aimed at "more competition" in that market. The situation is basically the same in all regional residential local access markets.

I will show that the above two "factual measurements" are poor indicators of the level of competitive pressures in those markets. Indeed, those facts may be credible indicators that competitive pressures are relatively intense, so much so that an entry strategy by new firms in that market is simply not profitable. I argue that the traditional measure of competition based on market shares is inadequate in the telecommunications industry because this industry has more characteristics of an emerging industry than of a mature industry. I argue moreover that the current approach to the regulation of telecommunications in Canada is likely to generate significant welfare harm to consumers and businesses as well as efficiency losses for the Canadian economy, in part because of the ensuing slower pace of ICT (Information and Communication Technologies) adoption by Canadian firms, especially small and medium size enterprises, induced by misdirected regulatory policies.

This calls for a significant and urgent review and transformation of the policies pursued and of the instruments used by the telecommunications regulator (CRTC). The current approach to economic regulation, mainly based on the tight control of incumbent local exchange carriers (ILEC) and light-handed surveillance of competitive local exchange carriers (CLEC), has run its course as market delineations become rapidly blurred with the increase in substitutability between communication products, services and technologies. Already, in different parts of the world, cellular/mobile telephony and fixed line telephony are engaged in neck-to-neck competition while they are both bracing themselves for the forthcoming rapid and full-scale deployment of the VoIP (Voice over the Internet Protocol) technology.

These developments challenge the traditional views of the telecommunications industry and the roles of the respective players (ILEC and CLEC of different types on different technological 
platforms) regarding universal service, infrastructure development, bundling/unbundling of services, inter-access at different nodes to networks whether they are proprietary or public, and wireline/wireless number portability; hence the need for significant reforms in the regulatory framework.

I claim that the urgently needed telecommunications regulatory reform must rest on three specific principles or policies for enhancing economic efficiency.

- First, the pursuit of a dynamic regulatory approach based on implementing proper competition processes and information systems rather than based on the traditional measurement of market shares and concentration ratios, which, in a changing and volatile industry, typically become obsolete at the time they are completed.

- Second, the promotion of competition through the determination of proper incentives

○ For the deployment of dynamically efficient network inter-access pricing rules and conditions

- For the implementation of efficient investment programmes to guarantee the integrity of the telecommunications networks in Canada.

- Third, the design of non predatory pricing rules (price floors) through full cost sharing capable of fostering the emergence of a more competitive telecommunications industry, even if such non predatory pricing rules is likely to imply some loss of static efficiency.

If the government (or the CRTC) wishes to adopt a pro-active strategy to favour the emergence of competition, based on the fact or belief that incumbents have an "unfair" advantage, then the preferred policy is a direct incentive subsidy, such as a generous but deferred investment grant or tax credit to be paid at some time in the future conditional on the entrant's capture of a predetermined market share. All potential entrants, and only those, with superior products or services, and/or superior technology, and/or better quality consumer service, who believe they can compete with and displace the incumbent one way or another, will enter or consider entering the industry. Inefficient competitors, fly-by-night operators and fast-buck seekers will stay out. Consumers and customers will reap the benefits of efficiency-enhancing competition through proper creative destruction. 


\section{THE RELEVANT MARKET}

The telecommunications industry looked very much like a mature industry in the 70's and even in the 80 's. But over the last 15 years the development of new information and communication technologies made the telecommunications industry appear much more like an industry in constant instability: new technologies, technology based convergence generating new products and new firms/competitors, significant level of mergers and acquisitions (new alliances) as well as divestiture activity, all these movements accompanied by significant changes in regulation, going from the omnipresent earnings based or rate of return based (cost plus) regulation towards a whole array of incentive, price cap, light handed, competition based, and competition prone regulation. ${ }^{1}$

The market for local access remains dominated, at least in terms of market share, by the Incumbent Local Exchange Carriers (ILEC) as the penetration of Competitive Local Exchange Carriers (CLEC) remains quite limited more than 10 years after the regulatory policy announcement aimed at increasing competition in that market. It is generally the case in the different regions of North America that ILEC still control well over $90 \%$ of the residential telephone wirelines. This lasting market-share dominance of ILEC in the residential local wireline access services appears somewhat as "an unexplained fact" or even "a surprising fact" for some industrial analysts and regulators, given the significant efforts to foster competition in that market.

Regulators in most if not all jurisdictions have forced incumbent firms who own the local loop (the last mile) of the wireline network to give access to their network to CLEC at relatively favourable conditions for those CLEC. In spite of such efforts, the level of access effectively demanded and used remains quite low, raising fears that ILEC may have been able, for some unknown reasons and through some obscure means, to prevent and/or block access, thereby maintaining their market power over the local wireline access services. ${ }^{2}$ As I will indicate

\footnotetext{
${ }^{1}$ In Canada, the most significant switch came in 1997 with CRTC Telecom Decision 1997(9). The first pricebased regulation regime covered the period 1998-2002; the regime was reviewed, modified and expanded in CRTC Telecom Decision 2002(34) for the period 2002(June)-2006.

${ }^{2}$ According to the CRTC 2003 Report on the Status of Competition in Canadian Telecommunications Markets, the Incumbents' local market share (lines) in 2002 was $93.3 \%$ in Ontario, 96.7\% in Quebec, and 95.2\% at the
} 
below, computing market shares in terms of the different competitors' numbers of home telephone lines over which they in fact provide their services is not the only way, or even the better way, to measure competitive pressures.

Indeed, market shares (whatever the way they are measured in practice) may not be the best measure of competitive pressures in a fast growing and technology-driven industry. The actual and potential competitive products and services in the telecommunications industry are in a constant state of flux. Besides the strictly regulated products and services, we see changes in products and services, appearing in a seemingly unpredictable manner, as well as changes in the prices, price structures (fixed or access charge, variable charge, bundled services discounts, etc.), restricted conditions imposed on different groups of consumers of those products and services, and even their technology delivery platforms, affecting their accessibility and flexibility of access.

The relevant actual market is therefore difficult to determine and the empirical studies that can be conducted at this time can only be incomplete and indicative or suggestive as to what is the real level of competition in the industry. Even the best state-of-the-art econometric studies available are subject not only to explicit caveats but also to a significant level of cavilling given the simplifications and aggregations in product characteristics and in pricing structures that researchers and analysts must inevitably have recourse to in their empirical estimation of demand structures for telecommunications products and services. The same is true of the numerous surveys trying to determine the demand and/or technological trends in the industry. One must treat these attempts very carefully and with scepticism. They may be quite often

national level, the market shares for the "residential" lines only being even higher. The report states: "There has been a limited amount of competitor penetration in the local and access segment since the introduction of competition in 1998. Competitors have typically been facilities-based competitive services providers who owns a portion of their PSTN [Public Switched Telephone Network] network facilities, or resellers of Centrex service purchased from either the incumbent or, to a limited extent, other facilities-based competitors. There has also been some limited market entry by cable service providers, and by utility telcos who can offer services using their existing infrastructure. Competitor entry has focused on the local business market in larger urban centres, though there has been some penetration in the local residential market in a limited number of cities." (p. 38). The main (large) incumbents include the following: Aliant Telecom, Bell Canada, MTS, SaskTel, TELUS, Teleglobe, Telesat Canada, and also Northwestel, Télébec, TELUS Québec. Moreover, 39 small incumbents are active in Canada, predominantly in Ontario and Quebec. The main facilities-based competitive service providers in 2002 include the following: Allstream, Call-Net, Microcell, 360Networks, FCI Broadband. The main resellers include the following: Primus, Distributel, and YAK. 
simply shots in the dark! Even if they may nevertheless contain some useful information, the use one may make of the results in order to fine tune the regulatory framework remains very limited.

Many factors affect the demand for telecommunications products and services such as wireline and wireless telephony and communications, whether by voice, email, short text messaging, chats, etc. First and foremost is the pricing of the different goods and services. But the pricing of telecommunications products and services is a complex variable to master.

\subsection{Pricing Structures}

In most cases, consumers face a menu of pricing structures and it becomes difficult, in empirical statistical or econometric studies, to summarize such pricing structures in a meaningful notion of what is the "price" of a product or service to be compared to the price of other (substitute) products or services. There are many reasons why telecommunications products and services are priced in such a way.

Menus of pricing structures or calling plans, according to which consumers pay a fixed charge per unit of time (typically a month) and then decreasing or increasing price levels for increasing consumption levels, ${ }^{3}$ are or can be implemented when the resale of the product can be controlled or deterred in such a way that the end consumer of the product can be identified by the producer or seller. Sometimes deterrence is achieved with the help of the law, as in the electricity industry where it is illegal to hook many households to one single metering device, but most of the times it is for economic reasons that joint or combined consumption is in fact deterred. Although it would not be illegal for a group of households to coordinate their needs so that they can use and share one single telephone line, whether fixed or mobile, it would be clearly extremely cumbersome and personally costly to achieve.

\footnotetext{
3 There are in fact many such structures, a situation that further complicates empirical estimation of price elasticities. In the case of wireline telephony in Canada, such price structures have been present mainly in long distance but not in local access. But for wireless telephony, even local calls have been in general subject to multipart tariff.
} 
Menus of contracts or calling plans have three important impacts: first, they promote efficiency and favour a faster development of the industry, second they generate higher profits through price discrimination, and third they allow product differentiation thereby softening competitive pressures.

Menus of pricing/contracts promote efficiency insofar as the marginal (last) units of service are sold at or close to marginal cost. Hence at the margin, that is, for the last communication units consumed, the most important allocative efficiency condition (marginal cost pricing, possibly equal to zero) is satisfied. ${ }^{4}$ The welfare value consumers attach to those marginal units is equal to the cost of producing or generating those marginal units. Hence the efficient social welfare maximizing level of production and consumption is achieved, at least once the decision to subscribe is made. However, a surplus may be lost if some of those potential consumers do not subscribe to the service because of the fixed subscription cost, whether a one time cost or a monthly cost.

Menus of pricing/contracts favour a faster development of the industry insofar as the industry products and services are at the margin priced at their lowest no-loss generating level, namely at a level which generate a zero marginal profit in order to maximize total (welfare) surplus, that is total gains from trade, conditional on consumers consuming a positive level. Firms will then try to capture a share of that maximized surplus through the pricing of infra-marginal units at levels above marginal or average costs. They can do so by trying to identify the willingness to pay or consumption patterns of different consumers, regrouping the consumers accordingly, and offering each group a preferred calling plan. In so doing, they price discriminate across groups or classes of consumers, allowing them to raising profits above what uniform pricing would generate. Finding the right profit maximizing balance in the menu of calling plans, as a best reply to similar strategies by competitors, is not an easy matter but one must trust the telecommunications firms with the competence and incentives to do so. Although multipart calling plans are not in general present at this time for local wireline calls (except in its simplest form of a fixed monthly access charge combined with an unlimited zero unit call cost), the

\footnotetext{
${ }^{4}$ Assuming that the productor service being exchanged has a positive value. In telecommunications, this need not be the case as the technology can be used to produce negative value products such as spammail. In any case, all technologies can be used properly and improperly.
} 
decision to subscribe or not to a wireline service or to a wireless service depends on the whole array of accessible services and their pricing, hence on the long distance pricing structure.

Carefully determining the calling plans limits and conditions allow telecommunications firms to differentiate their products and services from what competitors are offering, thereby softening the level of competitive pressures across the industry. Offering the same or very similar calling plans as those offered by another competitor (same limits, conditions and characteristics) would force the two firms to compete in prices only. As we will see, this latter type of competition is likely to end up in a money losing price war.

Many factors other than pricing drive the demand(s) for telecommunications products and services, in particular the choice between wireline and wireless, and eventually VoIP. To avoid competing strictly in prices, firms will compete along those other factors. Among the non price factors I may mention the following non exhaustive list: coverage (and dead zones), digital versus analog transmission, physical and design features of phones (such as colour, size and weight), battery life, DSL services and cable modem services, household composition, education, employment and occupation, security, commuting or not, etc.

\subsection{Non-Price Factors}

Consumers are most likely indifferent between the different forms or technologies by which they satisfy their needs for telecommunications services, as long as their demand for connectivity and flexibility, the two most important characteristics that they value, are comparable or at least similar in terms of quality and affordability. In most cases, consumers are not even aware of the technological characteristics of the platform on which their calls and other services are transmitted.

It is more, in fact probably exclusively, the end product that counts as measured or characterized in terms of connectivity, flexibility, safety, dependability, accessibility, capacity (high speed and broadband), and user-friendliness. In that sense, the demand expressed by consumers for different telecommunications devices (wireline, wireless, cellular mobile, 
satellite-based mobile, IP telephony, etc.) is a derived demand rather than a direct demand. The direct demand would be expressed, and should be empirically estimated, in terms of the above characteristics, namely connectivity, flexibility, safety, dependability, accessibility, capacity and friendliness.

It is not so much wireline telephony, mobile telephony under its different forms, or IP telephony, which is demanded but rather characteristics (virtual goods) such as the above connectivity, flexibility, safety, dependability, accessibility, capacity (high speed and broadband), and user-friendliness. Connectivity refers to the geographic area (or to the set of potential called/calling parties) over which communications can be established; connectivity is a multidimensional characteristic since it relies often on a multi-layer pricing plan: different connectivity at different prices. Flexibility refers to the availability of the service under different circumstances, the most important being certainly the availability throughout a given geographic area, as one moves around in the area. Safety refers to the health hazard one may be exposed to in using the service on a regular basis, an example being the concerns for safety which have prompted different jurisdictions to forbid the use while driving of handheld cell phones, in some cases all uses of cell phones. Dependability refers to the assurance of service of a high quality level, for example free of parasites and free of breach of confidentiality, when one needs it, especially but not only in an emergency situation. Accessibility refers to the availability of the service when one wants to communicate with another party. Capacity refers to the possibility to transmit vast amounts of information, such as large files, high definition pictures as well as videos, at a rate high enough to quasi-replicate in situ communications. User-friendliness refers to the ease of use of the technology and service.

It is because they can offer some combination of the above characteristics that the different telecommunications products and services are of interest to consumers. Clearly, none of the available telecommunications products and services dominates the others in every single dimension of every single characteristic.

It is clear that wireline telephony products and services have important advantages compared with products and services offered over different technological platforms. First of all, the 
quality, the capacity, and the reliability of voice and data transmission and the overall connectivity are much greater. However, they face also great disadvantages in terms of flexibility and mobility even if cordless wireline devices may allow some (very) short distance flexibility and mobility.

The 2003 telephone survey of Ipsos-Reid, commissioned by the CRTC, ${ }^{5}$ indicates that among three important factors influencing their choice between providers of long distance, cellular or Internet service provider, consumers chose the "price" as the most important factor, followed by the "quality of service", followed by the "convenience (having their service bundled with other services from the same provider)". When asked to choose the top two factors influencing their choice of local service provider, consumers mentioned the following: price (58\%), quality of service (45\%), reliability (31\%), convenience of single billing $(23 \%)$, convenience of service package (19\%), number portability (19\%). When asked whether it was easy to compare the prices and features of services between different providers, a majority of consumers stated that it was indeed easy (when applicable): for local service (62\%), for long distance (69\%), for cellular service (63\%), for Internet service (74\%).

Eventually, large scale IP telephony will change the competitive configuration between wireless and wireline by making fuzzier the relative advantages and disadvantages of those technologies. IP telephony has many advantages that till now have been specific to either wireline, such as quality and reliability of voice and data transmission and connectivity, or wireless, such as mobility and accessibility. It is therefore going to be a significant competitor for both wireline and wireless telephony on their own turf. The elusive no man's zone between wireline and wireless telephony is disappearing as the zone is soon to be claimed and occupied by IP telephony.

\subsection{Empirical Studies}

The best empirical estimates we would like to get at this time of the level of substitutability (and therefore competition) between wireline and wireless telephony is in terms of the own and

\footnotetext{
${ }^{5}$ Discussed in the CRTC 2003 Report on the Status of Competition in Canadian Telecommunications Markets.
} 
cross price elasticities of demands for those services. ${ }^{6}$ To run such empirical studies, one needs sufficient variability throughout the sample observations. If every observation unit in the empirical sample subscribes to a wireline service, then it is impossible to identify the decision variables behind or justifying the subscription itself. To do so, one needs within the sample a reasonable number of non-subscribers to the different wireline and wireless services, a condition which may not always be satisfied for the basic wireline services. However, it may still be possible to empirically estimate the relative importance of the explanatory variables, drivers or shifters, of the usage level (like minutes) of the services.

In terms of data requirements, it is clearly preferable to have household level data rather than more aggregated regional data. A recent study of wireline-wireless communications substitution behaviour using household level data reports own-price elasticities of mobile access demand of the order of -0.43 to -0.60 and cross-price elasticities of the order of +0.13 to +0.18 with relatively high degrees of precision. Hence, the wireless telephone service is a relatively significant substitute for wireline telephony. For second fixed line access, the results are even more compelling with own-price elasticities of the order of -0.65 to -0.69 and crossprice elasticities from mobile prices of the order +0.22 to +0.26 although the latter are not statistically significant at the usual confidence levels. ${ }^{7}$

Those results also suggest that wireline and wireless telephony may be, for a significant number of consumers, complements rather than substitutes although the negative (net) cross-price elasticities indicate that on average the substitution effect dominates the complementary effect. The development of a larger number of different telecommunications technologies, each with important specific characteristics (connectivity, flexibility, safety, dependability, accessibility,

\footnotetext{
${ }^{6}$ In the jargon of economists, the price elasticity of demand is a measure of sensitivity of demand to a positive change in price: it is measured by the ratio of the percentage change in the quantity demanded over the percentage change in the price. One obtains the own price elasticity (negative) if the price that changes is the price of the product considered and the cross price elasticity if the price that changes is the price of another product, either a complement (negative elasticity) or a substitute (positive elasticity).

${ }^{7}$ M. Rodini, M.R. Ward and G.A. Woroch, Going Mobile: Substitutability between Fixed and Mobile Access, December 2002. Those authors used household level data from the "Bill Harvesting data [set] from TNS Telecoms ReQuest Market Monitor ${ }^{\circledR}$ along with its survey response" (see www.tnstelecoms.com). The estimate for the cross-price elasticity of fixed line telephony (all lines combined) from mobile telephony prices is lower (of the order of +0.06 to +0.08 ), as expected insofar as the main effect should be on second fixed lines.
} 
capacity, friendliness), tends to increase the global usage level of all telecommunications technologies. However, the composition of such a higher usage may be asymmetrically distributed and differentially shifted over time across the different technologies. In such a context, the net empirical estimates of substitutability, as measured traditionally by the crossprice elasticities, could lead to a significant downward bias in the measured or perceived level of competition in the local access market.

Computing market shares in terms of home telephone lines is not the only way to measure concentration. In fact, it appears now to be an outdated way to do it. Indeed, a recent study by Bell Canada ${ }^{8}$ indicates that the market share of wireline voice communications (fixed line calls) originating from home, expressed in terms of minutes of voice communications through all technologies, is about $80 \%$. Given that people can call from home using Bell Canada (ILEC) fixed telephone lines or cellular/mobile phones, this approach to measuring market shares is clearly better. On that basis, the Canadian regulator (CRTC) should be somewhat less nervous than it appears to be regarding the state of competition in residential local wireline access services, once the view shifts from local residential wirelines to local residential voice communication services, both wireline and wireless.

Bell Canada study is the first such study and it is most welcome insofar as it is based on real usage rather than surveys of intentions of use. It complements in a significant way the previously released survey study ${ }^{9}$ which had shown that $49 \%$ of Canadian cell phone subscribers use their cell phone at home even if they have access to a fixed wireline phone nearby. The significant rate of growth of wireless communications observed in CRTC own data showing a Bell Canada's share of less than $40 \%$ indicates rapidly growing competitive pressures for Bell Canada as an ILEC.

\footnotetext{
${ }^{8}$ Bell Canada, Analysis of Local Residential Voice Network Usage, April 2004. The study covers the period January $1^{\text {st }}$ to February $29^{\text {th }} 2004$.

${ }^{9}$ DECIMA Research/Bell Canada, Canadians' Usage and Views Regarding Telecommunications Markets, October 2003
} 
A more recent study ${ }^{10}$ captures more adequately the recent developments in competitive pressures in Telecommunication services. The authors compare trends in the numbers of residential wirelines (primary, secondary or total) serviced by Bell Canada in Ontario and Quebec with the observed number of such wirelines over the period January 1990 to February 2004. ${ }^{11}$ Their results indicate that a significant and increasing discrepancy between the predicted and the observed lines serviced appears starting in January 2000, which the authors associate very convincingly to increasing competitive pressures. ${ }^{12}$ This study is the most recent and most credible one regarding the level and impact of the competitive pressures exerted by competing technologies (wireless and high speed internet connections) on primary and secondary wirelines in service. It shows a significant and increasing (cumulative) level of competitive pressures.

\section{THE LEVEL OF COMPETITION}

However, one must recognize that many consumers do not have access to wireless telephone technology and depend completely on their fixed telephone lines. Insofar as this sub-segment of the consumer population needs protection against the possible market power of the ILEC, the CRTC might be justified to keep pressing for more competition. This does not mean that the traditional price control regulation is still needed. In fact, new tools are warranted given the significant changes and dynamic characteristics in the industry. I cover such questions below. The central issue is to determine what should be the "measured" level of competition between local wireline and wireless voice communications deemed sufficient to consider that the two constitute one single market in which competitive pressures would be strong enough to prevent incumbents from exercising market power. If and when such a level is achieved, one should expect the CRTC to relax its direct price controls and also its pressure for more competition in the local wireline access market. I will argue here that the dynamics of competition in the local

${ }^{10}$ K. Dzieciolowski and J.G. Galbraith, Indicators of Wireline/Wireless Competition in the Market for Telecommunication Services, CIRANO 2004RP-21, 2004.

11 The trends obtained from the data for the January 1990 to December 1999 period "were in each case constructed from projection on twelve linearly-additive monthly dummies (i.e. summing to the constant) for seasonality and on the cumulative sum of housing-unit starts in Ontario and Quebec for trend growth, as well as an autoregressive term to capture short-term deviation from the trends." (p.15)

12 The CRTC 2003 Report on the Status of Competition in Canadian Telecommunications Markets mentions "the number of local lines decreased by $2.4 \%$, from 21.1 million lines in 2001 to 20.6 million lines in 2002." (p. 37) 
telecommunications services does call for a review of regulatory ways and means of intervention.

Let us first consider the level of substitutability in the local telephone market between wireline and wireless communications. The standard approach of antitrust economics is to consider the level of competition as sufficient to prevent an undue exercise of market power by incumbents if those incumbents would find unprofitable to implement a small but significant (typically 5\%) and non transitory (typically for one year) increase in price (SSNIP) for their services, given the pricing structure of their competitors' products and services. Such a move would be profitable if the reaction of consumers to such a price increase for one year were relatively small and limited, that is, if there were no close substitutes to which they can turn to offset the impact of that price increase.

To do so, one must define the relevant market, the relevant choice set that consumers face regarding the satisfaction of their telecommunications needs, and the relevant set of competitors to determine the level of competition in the telecommunications industry. These questions can be raised in the study of any industry or industrial sector but are particularly important in the context of the telecommunications industry, which has many characteristics of an industry in its early phases of development rather than a mature industry, a rather striking example of the "back to the future" storyline.

In that same vein, the relevant market is the minimal group of products and services and/or geographical areas such that this test can be met. Clearly, the important variable here is the substitutability between products and services from the point of view of consumers. If for instance Bell Canada could, in the absence of price controls, profitably increase its price of local wireline telephone services by $5 \%$ for a period of at least one year, then this simple fact would indicate that the capacity of consumers to switch to alternative local telephone services (cellular/wireless, VoIP, other wireline providers) is sufficiently limited that local wireline telephone services would be considered to be the relevant market in this case. If the firm needed a similar raise in the prices of alternative services to profit from such a price increase 
( $5 \%$ for at least one year), then the relevant market would be defined as including such alternative services.

Given the elasticities computed by Rodini, Ward and Woroch (2002), the local wireline telephone services would be considered as one relevant market because the elasticity figures indicate that the level of competition may not be strong enough, at the time of the study, to prevent a profitable increase of the price of local wireline telephone services by $5 \%$ for a period of at least a one year. However, one must realize that such estimates must be used with extreme care given the empirical difficulties mentioned before, in particular the downward bias in the estimate of competition intensity, which may be unavoidable in such studies. In fact, for the reasons developed in the next paragraphs, price deregulation should be high on the regulator agenda. The regulator must still ensure that predatory pricing is adequately controlled, an issue I cover below.

From the study reported above, there are reasons to believe that the level of competition, measured by the substitution potential, as revealed by consumers in their choice of communications channels, between local home wireline and wireless phone communications is still not high enough to warrant a complete price deregulation in the local wireline communications market. But there are reasons also to believe that it is time to proceed with partial price deregulation. On the basis of Bell Canada study referred to above, ${ }^{13}$ the market share of Bell's wireline services in total local communications services measured in effective minutes of communications stands now at about $80 \%$. Given these results one would expect, from the dynamics of competition between wireline and wireless services in the industry (excess capacity, number portability, low switching costs, increased quality and reliability of the wireless, etc.) that it would be impossible for Bell to profitably raise its prices for wireline services by $5 \%$ for a period of one year. Hence, from the rules followed by the Competition Bureau of Canada, competition would be deemed sufficiently intense in the industry.

\footnotetext{
${ }^{13}$ Bell Canada, Analysis of Local Residential Voice Network Usage, April 2004. The study covers the period January $1^{\text {st }}$ to February $29^{\text {th }} 2004$.
} 
The ever-increasing number of consumers having access to both technologies and having access soon to a third one, the VoIP technology, continuously reduces the need for protection. The level of market power of the ILEC is seriously diminished up to a point where more regulation may cause more harm than good. Insofar as those consumers who have already the possibility to react to any price increase by switching to alternative modes of telephone communications cannot be isolated from other consumers, that is, cannot be offered a specific pricing plan, the wireline incumbent will have to balance the benefits from an increase in the price with the loss of revenues due to such switching. Hence, on that basis alone, one would be inclined to recommend immediate deregulation even if some consumers have, by choice or not, access to wireline local telephony only.

The potential future competition in products and technologies also play an important role and defining the set of competitors, actual and potential, is a critical step in determining the level of competition. The identity and role of potential competitors is difficult to determine since many products and services as well as some future providers may simply not be yet identified even though they may be dans les coulisses and certainly present in the minds of incumbents, whether they are wireline, wireless or VoIP providers. Any empirical study of the type econometricians usually do cannot avoid neglecting such crucial aspects. The recent Fido (surprising) offer in southern British Columbia, ${ }^{14}$ allowing unlimited local area calls combined with competitive long distance rates, and the recent NTT DoCoMo ${ }^{15}$ (even more surprising) announcement that it will market in the near future "FingerWhisper", a noiseless mobile wristwatch telephone making use of the user's hand as an integral part of the telephone, ${ }^{16}$ are such examples. Similarly, Comcast, the largest U.S. cable television company, announced in late May 2004 its plans to offer VoIP telephone service to more than 40 million households by 2006; in so doing, it follows a host of other cable operators, such as Cablevision Systems, Cox Communications, and Time Warner Cable, challenging local telephone companies. In Canada,

\footnotetext{
${ }^{14}$ Microcell has already announced plans to offer very soon such a service in Toronto and other major metropolitan areas.

${ }^{15}$ According to its website, NTT DoCoMo is Japan's premier mobile communications company and is the world's leading mobile communications company with more than 48 million customers.

${ }^{16} \mathrm{See}$ www.nttdomoco.com/corebiz/ubiquity/fingerwhisper.html
} 
Videotron, ${ }^{17}$ a major cable operator, announced in late July 2004 its intention to deploy local telephone services by 2005 using the VoIP technology, which it did. One may expect that other major cable operators, such as Rogers Communications ${ }^{18}$ and Shaw Communications, ${ }^{19}$ Vonage Canada, ${ }^{20}$ as well as Internet provider AOL Canada, ${ }^{21}$ will join in to exploit the much coveted VoIP technology in order to increasingly offer local telephony access across Canada.

In July 2004, PRIMUS Telecommunications Canada Inc., which according to its website is the largest alternative communications provider in Canada with over 1 million customers, announced that it will offer, as soon as in Fall 2005, wireless services through the national PCS (Personal Communications Services) network of Microcell Solutions Inc., thanks to a multiyear agreement between the two firms. Access to Microcell's network will allow PRIMUS to reach over $80 \%$ of all Canadians living in urban areas across Canada. According to the press release, “... the services will be marketed under the PRIMUS brand and will leverage PRIMUS' existing facilities-based national network to carry long-distance traffic. For the first time, Canadians will be able to fulfill all of their telecommunications needs with PRIMUS, including

${ }^{17}$ According to its website, Vidéotron Ltée, a wholly-owned subsidiary of Quebecor Média inc., is, according to its website, an integrated communications company active in cable television, interactive multimedia development and Internet access services. In Québec, Vidéotron serves 1,429,000 cable customers and 287,000 digital TV customers. Vidéotron is also the leader in high-speed cable Internet access throughout Québec with 473,000 Internet customers (cable modem and dial-up modem).

18 According to its website, Rogers Communications is Inc. is a Canadian national communications company, which "is engaged in cable television, broadband Internet access and video retailing through Rogers Cable Inc.; digital PCS, cellular, wireless data communications and paging through Rogers Wireless Communications Inc.; and radio, television broadcasting, televised shopping and publishing businesses through Rogers Media Inc. Rogers Wireless Communications Inc. is one of Canada's leading wireless communications service providers with network coverage in Canadian cities from coast-to-coast, offering a complete range of wireless solutions including Digital PCS, cellular, advanced wireless data services, two-way text messaging and paging to customers across Canada. Rogers Wireless Communications Inc. is approximately 56\% owned by Rogers Communications Inc., and 34\% owned by AT\&T Wireless Services, Inc. with the remainder publicly held."

19 According to its website, Shaw Communications is a diversified Canadian communications company whose core business is providing broadband cable television, Internet and satellite direct-to-home ("DTH") services to approximately 2.9 million customers. In June 2004, Shaw Communications announced that it is planning to launch VOIP or telephone service in early calendar 2005.

${ }^{20}$ According to its website, Vonage technology, using an existing high-speed Internet connection, enables anyone to make and receive phone calls - worldwide - with a touch-tone telephone. Offering quality phone service bundled with enhanced IP communications services, our interactive communications portal is a gateway to advanced features only available through digital telephone service. Utilizing our global network and advanced routing technologies, Vonage offers an innovative, feature-rich and cost effective alternative to traditional telephony services."

21 AOL Canada Inc. is a strategic alliance between America Online, Inc., a wholly owned subsidiary of Time Warner, and RBC Royal Bank, the personal and commercial banking division of RBC Financial Group. 
wireless voice and data, high-speed Internet, long-distance, traditional local line, and Voice over Internet Protocol (VoIP) services.”

Moreover, as I stressed above, telecommunications products and services must be seen as a "technology" to generate a vector of communications (and entertainment) characteristics that customers value. A consumer is likely to express his/her demand for a given product or service in terms of its contribution to the overall connectivity, flexibility, safety, dependability, accessibility, capacity and friendliness of his/her portfolio of products and services, which are offered or distributed through different technologies (wireline, Internet access, many mobile lines, etc.). It is not the specific stand-alone characteristics of any given service that are likely to count but their contribution to the individual communications portfolio. This has important impacts for our understanding of the proper regulatory approach to competition in telecommunications, in particular in the local wireline access. A product-by-product or marketby-market approach may turn out to be very detrimental to the welfare of consumers because it is likely to miss the interdependencies between products and services and the specific contribution of a product or service to the group or portfolio of telecommunications means, products and services, a customer may have access to.

It is important here to mention two factors that may possibly, but not necessarily, impede the development of competition in the local wireline access market. The first one is the bundling of services with single integrated billing, which makes it more costly in time and trouble for the consumer to move between providers and more difficult for new competitors to enter and confront the incumbents. The second one is the absence of number portability between wireless providers and between wireless and wireline providers (WWNP), which also makes it more costly for costumers, especially business customers, to switch between providers.

Single billing and the absence of WWNP are critical elements which may increase the cost of change or switching between providers and therefore allow those providers to raise prices for "old" customers while pursuing aggressive pricing and calling plans for "newcomers", as we see for instance in the credit card business and in the insurance business. However, according to Videotron, customers wishing to shift from Bell to Videotron will be able to keep both their 
telephones and their number(s). ${ }^{22}$ So WWNP is quickly becoming a reality and may not be a significant problem anymore. As for single billing, it favours the bundling of communications and entertainment products and services which may be anti-competitive for old customers but at the same time very pro-competitive at the margin for new customers and for attracting specific well defined groups of customers from other competitors. Both the credit card business and the insurance business are good examples among others of such developments. Given the efficiency of such a billing procedure for the consumers and given the wide acceptance of the practice, one would rely on the consumers to discipline the sellers by keeping a close look at the competitive offers of alternative services by competitors. Besides WWNP, it might be desirable to develop and implement a single billing portability (SBP) concept and procedure so that consumers can avoid falling hostage of the firms' billing strategy.

Clearly, all providers of integrated communications services are moving in the direction of single billing, both for efficiency, convenience and competition reasons and for strategic loyalty-building reasons. The way for the regulator to ensure that single billing does not unduly restrict competition is not to fight it or regulate it in such a way that it would be impossible or impractical to implement but rather to take a pro-active stance: make sure first that customers are well aware of competitors' offers (services and pricing plans) and second that switching from one competitor's single billing plan to another competitor's single billing plan is easy and cheap. In any case, for the sake of promoting competition, all competitors in the broad communications field must be subject to similar regulations regarding single billing.

\section{THE COMPETITIVE ENVIRONMENT}

The telecommunications industry appears at this time to be an industry in its early phases of development rather than a mature industry. The level of competition in those early phases is in general much higher that in the later phases when the industry becomes a mature industry with a relatively stable dominant technology (or technologies) and a relatively stable set of competitors. $^{23}$ Hence, the danger of over-regulating the industry in those early phases is even

\footnotetext{
${ }^{22} \mathrm{http}: / / \mathrm{www} . v i d e o t r o n . c o m /$ services/static/fr/pdf/telephonie_en.pdf

23 See for instance Boyer, M., Lasserre, P. and M. Moreaux, "Real Options, Preemption, and the Dynamics of Industry Investments" (CIRANO, 2005 revised), and also Boyer, M., Lasserre, P., Mariotti, T. and M. Moreaux, "Preemption and Rent Dissipation under Bertrand Competition," International Journal of Industrial
} 
greater than in the later phases. Regulation must be handled with extreme care to avoid hampering the development of real value generating competition.

Therefore, one must look at local wireline access competition from a "process" point of view rather than from a "market share" point of view. This makes the analysis slightly more difficult and complicated but at the same time more transparent, more adequate, and better fine-tuned to the characteristics of the telecommunications industry.

The process approach to fostering competition stresses the process rather than the results. It concentrates on ensuring open access to the existing network facility at properly defined competitive access pricing and conditions rather than on the number of firms demanding access or the market shares of those firms as compared with the incumbents' market share. In so doing, it avoids opening the doors to inefficient competitors who may benefit from the regulators' over emphasis on market shares at the expense of consumer welfare.

If not properly addressed, these developments may turn out to be value destroying by reducing the incentives to invest in developing and maintaining infrastructure capacities that are prone to social inclusion, in particular in terms of the obligation to serve. The situation is even more dangerous if potential competitors are in fact unwilling to enter the (residential) local wireline access market at any cost! ${ }^{24}$ We will see next that there are good reasons to suspect that this may indeed be the case and that the regulators are ill advised to concentrate their attention on market shares rather than on the competitive process. The process approach to fostering competition is also likely to ensure a level playing field for all competing players while at the same time recognizing the different responsibilities of those players, especially in developing and maintaining infrastructure capacities.

It is important to understand the competition model relevant for the telecommunications sector, including the pro-competitive or anti-competitive role of the following factors: the number of

Organization 22(3), 2004, 309-328. Note to the reader: these are abstract academic papers making use of advanced mathematical reasoning and techniques, to be consumed with moderation.

${ }^{24}$ In spite of its increasing presence in households in Canada, Internet access is far from coming close to meeting a test of "obligation to serve", for instance in providing a 911 service. In that sense, the reliance of industry competitors on that technology could mean a reduction of social inclusion. 
competitors, the substitutability between the different products and technologies, the existence of excess capacity. Equally important is the understanding of the entry and exit strategies of competitors (based on "ex post entry" market conditions rather than on the "actual ex ante entry" conditions) as well as the dynamic incentives for R\&D and innovation. Let us consider those in sequence.

Consider an industry with the following three characteristics: firms are engaged predominantly in short run competition, the products of the different firms are close quasi-homogenous substitutes, the firms have no binding capacity constraint and can produce up to the market demand at a common quasi-constant marginal cost (with some fixed costs). In such an industry, a Bertrand industrial equilibrium ${ }^{25}$ will most likely emerge. In such an equilibrium, the competition between the firms, which are eager to increase their market share by pricing their product slightly below their competitors' price, will make prices fall towards the marginal cost level and therefore generate negative profit levels given by the negative of the fixed costs. Such a situation is of course extreme but it is nevertheless quite instructive. It shows that a strategy to enter into an industry characterized by product homogeneity, constant marginal costs (excess capacity), and short run competition is likely to be a money losing strategy. Hence, entry in such an industry is very unlikely. Entry by competitors in such an industry cannot be expected unless those Bertrand competitive conditions can be changed or by-passed and controlled in some ways. Hence, the importance for the competitors to plan their entry in the industry with a strategy aimed at avoiding the Bertrand competition conditions.

A firm could profitably enter with a differentiated product (possibly and preferably offered through a different technological platform) in terms of those characteristics valued by the consumers, namely connectivity, flexibility, safety, dependability, accessibility, capacity, and user friendliness. Given the diversity of consumers' tastes and needs, there may be a niche in which the firm can enter and make profits. A firm could also profitably enter into the industry with a limited capacity (using a "judo" economics strategy) such that the incumbent will find it unprofitable to engage in a price war in order to prevent the small and limited loss of customers

\footnotetext{
${ }^{25}$ Named in honour of Joseph Bertrand, a French mathematician and economist of the late $19^{\text {th }}$ century who first analysed this type of competition in the Journal des Savants, 1883
} 
that the capacity constrained entrant can attract. The telecommunications frenzy of the 1990s, both in terms of capacity investments and technological developments, led to a 500-fold transmission capacity increase while demand itself increased by a phenomenal 4-fold. It is estimated that 200B $\$$ of telecommunications network capacity was built unnecessarily (expost). This building of over capacity in a 'commodity' market brought the telecommunications industry in the Bertrand competition trap. ${ }^{26}$

A firm could also profitably enter with a set of products and services relatively similar and homogenous to that of the incumbent and with a relatively large capacity, thereby credibly signalling to the incumbent that it is entering for the long term. If the entrant's strategy is sufficiently convincing, the incumbent may find more reasonable and profitable to respond to entry by adopting an accommodation strategy in order to avoid a likely unsuccessful but potentially very costly price war. In the repeated competition game, the firms may be able to find mutually beneficial accommodation strategies avoiding the Bertrand competition outcome. $^{27}$

But entering with such a strategy is quite risky given that the incumbent may not be convinced that it is in its best interest to accommodate entry. Inducing an entry accommodating reaction by the incumbent will in general require that the entrant either incurs significant investment outlays as sunk irreversible investment costs, or signs contracts with important customers with conditions that are very costly for the provider for renegotiating or breaking the contract, or adopts a bridges-burning (no escape) strategy to clearly and convincingly signal to the incumbent its forceful intention to remain in the industry (by raising its cost of exiting).

That is how we must understand the competition for the residential local wireline access and why entry in this market has been so weak even after multiple pro-entry decisions and actions by telecommunications regulators over the last 10 or 15 years. The residential local wireline

\footnotetext{
${ }^{26}$ See also The Economist (2003.10.09). The impacts of the emergence of Bertrand competitive conditions in an industry can be quite significant: the Canadian gem Nortel saw its capitalization falling from 400B $\$$ to $3 \mathrm{~B} \$$ in two short years between the summer of 2000 and 2002, one of the main reasons being the large overcapacity in the industry.

${ }^{27}$ The 2005 Nobel prize winners in economic science, Thomas Schelling and Robert Aumann were pioneers in the development of such competitive modeling.
} 
market is most likely to be characterized by Bertrand competition conditions: short run competition (favoured by the CLEC immunity regarding the development and maintenance of the network capability, which makes entry in the industry almost as easy as exit from the industry), homogenous product or service (there is arguably nothing more homogenous in the telecommunications industry than the local wireline services offered by two different providers), constant marginal cost (with this marginal cost being very low), and potentially no binding capacity constraint (by getting access to the whole local wireline network at low cost).

The judo economics strategy mentioned above can explain the fact that small (capacity constrained) entrants have captured a small market share in the residential local wireline access market. In such a context, it is better for the incumbent to let the entrant survive with limited capacity than engaging in a strong competition over the entrant's market share, which is most likely to end up in a money-losing situation. If and when entrants eventually capture a large enough market share, it may become profitable for the incumbent to engage in a price war, unless some other Bertrand condition can be neutralized, for instance replacing the short run competition strategies by a longer term understanding of common interests, thereby favouring over time some form of tacit softening of competition between the different providers. But before such a situation occurs, we will keep experiencing wireline local access market share dominance by the incumbent firms.

Therefore, unless the Bertrand conditions can be neutralized in the competition over local wireline services, there is little chance that competitors will indeed show up in that market (except in the form of small non threatening actors) even if regulators take pro-entry actions and even if the current pre-entry profits of the incumbents were high. It is the post-entry competitive conditions, post-entry prices, and post-entry profits rather than the corresponding pre-entry levels, which are the drivers behind the entry strategies of potential competitors.

Understanding and anticipating the likelihood that Bertrand competitive conditions will emerge post-entry in the residential local wireline services market, competitors who want to enter the telecommunications industry in Canada will prefer investing in other markets and/or technologies (cellular mobile, satellite mobile, IP telephony, VoIP telephony, etc.) allowing 
them to market products and services that have different characteristics thereby softening competitive pressures. The capital necessary to credibly challenge the incumbents in the local wireline access markets is clearly available. But it is not deemed profitable to invest in such a strategy given the likelihood of post-entry Bertrand competitive conditions in that market.

The facts that entrants (the CLEC) have been relatively hesitant to capture a larger share of the local wireline market in spite of efforts by the CRTC to manage competition in their favour, in particular restraining the incumbents' capacity to respond to competitors' entry (regulating ILECs' prices but not CLECs' ones; forbidding winback actions by ILECs for a certain period; etc.), and have preferred to invest huge amounts of capital in those alternative technologies give credibility to the above analysis.

Entry in the local wireline market is clearly not an easy policy to pursue and could potentially be a very risky strategy. One may expect that entrants will prefer to invest in other segments of the telecommunications industry. However, this is not peculiar to the telecommunication industry and markets. Similar difficulties and risks are present in most industries. Indeed, incurring losses during the early phase of entry is quite common for most if not all entrants in any industry. Such a situation would not justify a regulatory intervention to protect entrants from the competitive pressures they will be confronted with. When Toyota decided in the fifties to challenge the major incumbents of the time in the automobile industry, it came in with a superior technology and eventually a better product. There were no calls for protection from the incumbents through price and marketing controls (except for the legal provisions forbidding predatory pricing). The company made the risky gamble that its value chain model was better, that is, would lead to lower costs and higher quality, than the value chain model of the big three of the day. And that is the way competition serves customers through creative destruction. In the telecommunication industry, such creative destruction could come from incumbents entering into each other markets or from new entrants capitalizing on their expertise in a related industry (cable or satellite communication services for instance). Many other examples could easily be given. 


\section{A RENEWED PRO-COMPETITION REGULATORY FRAMEWORK}

The real conundrum of the regulator is to create and enforce static competitive conditions between the current bundles of products and services or technologies as well as dynamic competitive conditions yielding strong intensity of incentives for developing new technological platforms, introducing new products and services that could be both cheaper and more efficient, connectivity-wise and flexibility-wise, and in so doing replace the current goods and services and possibly their producers and distributors. To achieve a proper balance between short run (static) and long run (dynamic) goals, regulators must rely on competitive processes, that is, they must make sure that their interventions are not aimed at micro-managing prices and quantities but rather at making sure that those prices and quantities emerge from a competitive environment. Micro-managing prices and quantities is very much reminiscent of the old regulatory framework (rate-of-return regulation for instance) that led the regulator to discover through adversarial proceedings the "true" cost functions of the firms. We know now that this objective was futile: economic costs are not accounting costs. Exerting a proper level of competitive pressures is the only way to induce the firms to really minimize the costs of their portfolio of goods and services, that is, to make the accounting costs close or equal to the economic costs.

A pro-competitive regulatory framework must accept and rely on the fact that the telecommunications industry is an emerging industry rather than a mature industry: it is characterized by significant technological uncertainty, a volatile flow of new products and services, and a volatile set of competitors, actual and potential. Balancing and achieving the complementary but sometimes conflicting objectives of static efficiency and dynamic efficiency in such a volatile environment will more likely be met by a competitive processes view of regulation rather than by a more traditional "market shares" approach.

Insofar as the CRTC's policies are not consistent with a competitive processes view of regulation, the current approach to the regulation of telecommunications in Canada is likely to generate significant harms to consumers and losses for the Canadian economy. We need a significant and urgent review and transformation of the policies and means of the telecommunications regulator, with a stronger accent put on its three crucial roles as the trusted 
generator of information for the consumers, as the manager of the level playing field conditions, and as the promoter of efficient investment programmes.

The competition processes view of regulation developed below stresses the importance of competition as the most powerful and efficient generator of social efficiency in the telecommunications industry. Benevolent regulation can, under complete and perfect information, favour the emergence of an efficient allocation of resources in a partially natural monopoly industry such as telecommunications (proper goods and services as well as prices, proper investments in technologies, capacity building, and network maintenance, etc.) and in so doing can dominate competition. But in an incomplete information (on technologies, consumers' preferences and needs, and R\&D and investment opportunities) situation such as the one prevailing in the telecommunications industry today, it is these competitive processes and pressures that can generate the better allocation. The proper reference point here is not the full information best allocation but rather the incomplete information better allocation. Many conflicts regarding the regulators' role, ways and means, stem from this ill-conceived comparison between an infeasible full information best allocation and a feasible better allocation: the best is here clearly the enemy of the good.

Competition in this network industry can be achieved over time through the following:

- The promotion of dynamically efficient network inter-access rules and conditions;

- The promotion of efficient investment programmes to guarantee the integrity of the telecommunications networks;

- The promotion of non predatory pricing rules (price floors) and behaviours based on full cost sharing procedures capable of generating significant gains in dynamic efficiency even if such pricing rules imply some loss of static efficiency; this loss in static efficiency can be adequately controlled by making sure that a stronger accent is put on the crucial roles of the telecommunications regulator as a trusted generator of information for the consumers and as the manager of the level playing field competitive conditions.

\subsection{The regulator as trusted generator of information for customers}


The possibility and desirability to better inform customers about the characteristics, including pricing, of different (packages of) telecommunications goods and services should, in the context of an emerging industry such as telecommunications, be a well-understood role of the regulator. As I mentioned before, the complexity of the pricing structures allows competing firms to soften price competition. A regulator, capable to inform customers as to the real costs and benefits of the different packages on the market in terms of their intended use or consumption could go a long way in promoting competition without engaging in micromanagement of prices. It should be relatively easy to set up the infrastructure necessary to meet the information needs of customers and respond to their implicit if not explicit demand for comparative information on alternatives. As in any industry, better customer information is a strong factor of competition and economic efficiency.

This regulation by information approach is not new but it is too often neglected as if customers of complex goods and services were individually able to make and understand comparisons of pricing and other characteristics such as connectivity, flexibility, safety, dependability, accessibility, capacity, and user-friendliness of telecommunications services. In an industry such as telecommunications, the generation and presentation of such information in a userfriendly way should be a role and responsibility of the regulator, at least till the customers develop such a capability of their own. Asking the regulator to assume such a responsibility could prove very important for efficiency and political acceptability during the transitory period towards a complete deregulation of the telecommunications industry.

\subsection{The regulator as promoter of efficiency in network development}

Regulators generally recognize that substituting competition mechanisms for costly imperfect regulation could improve cost efficiency as well as allocative efficiency. But for network industries, it is not necessarily desirable to introduce competition in all segments. Some segments of a network, which are unavoidable inputs for the potentially competitive segments, may be subject to significant economies of scale. These essential facilities, specific to a given technology, could remain price regulated as long as alternative technologies, allowing those 
segments to be by-passed are not available. Traditional examples include rail transportation (bottleneck: tracks; potentially competitive segments: passenger and freight services) and electricity (bottleneck: transmission and distribution grid; potentially competitive segment: power generation and retail sales). In telecommunications, the traditional example was (bottleneck: local loop; potentially competitive segment: long distance) but new technologies such as wireless telephony, cable telephony and VoIP telephony now make the local loop much less of, and probably not anymore, an essential facility. However, the local wireline may still represent a non-standard natural monopoly. Even though it is challenged by the above competing technologies, it would not make sense to duplicate the wireline access to residential or business customers. What is needed is open (inter)access to all bottleneck network facilities on all technologies at proper prices and conditions.

To access bottleneck facilities, entrants or competitors pay an access price (regulated) and the incumbent must grant access to all firms on an equal, non-discriminatory basis. Under this regime it is important to get the access price right. If it is "too low", then the incumbent has low and inadequate incentives to invest and innovate, a subsidy is provided to the entrant, and inefficient entry is encouraged. If the access price is "too high", competitors have an incentive to inefficiently bypass the incumbent's facilities, efficient entrants are discouraged from entering, and competition is not likely to prevail.

The promotion of efficiency in network development investments is a role and a responsibility that the telecommunications regulator should assume. The main reasons are threefold:

- Investments in network development are typically large long-term irreversible investments with significant economies of scale making the platform a non standard natural monopoly;

- The different network development strategies offer significantly different levels of embedded managerial flexibility to delay or advance the development timing, to slow down or speed up the pace of development, to increase or decrease the size of the network, and to raise or reduce the quality of the network infrastructure as new information on significantly volatile demands and costs is gathered over time; 
- The volatility of demand and costs together with the relative embedded managerial flexibility and the significant irreversibility of investments in network development require new evaluation methodologies (real options valuation), which are still underutilized or poorly so by network operators.

In such a context, the regulator must make sure that inter-access to essential or bottleneck facilities is available, at proper non-discriminatory conditions and prices, to foster entry by more efficient providers. ${ }^{28}$ The regulator must also recognize that the proper non-discriminatory conditions and prices must account for the real options that are exercised, as the network is being built or developed. Eventually, the network developing firm is stuck with the technological characteristics of its realized network. Exercising those real options can represent a significant cost in network development and must therefore be accounted for in determining the proper non-discriminatory access prices and conditions that will govern the use of the incumbent's network by competitors. Unless a proper account is made of those real options related costs, the development and maintenance of the telecommunications networks are likely to be inefficient, thereby imposing significant real costs on society.

Volatility, irreversibility and managerial flexibility are also at the core of the new approach to modelling entry decisions. Hence, even if the entry decision may be seen at first glance as unprofitable, the real options value of entry may tilt the balance in favour of entry. The decision of a firm to enter or not a given market such as the local wireline services market will depend not only on the expected return it can realize on such an investment but also on the value of the real options that entry may create for the firm. The value of those real options represents the value of the firm's capacity and flexibility to adjust its operations as it becomes better informed of the market possibilities. ${ }^{29}$ Having access to this information may require first a presence in the market. The proper evaluation of real options that are accessible only once entry is realized

\footnotetext{
${ }^{28}$ For a presentation and discussion of access pricing rules, see Marcel Boyer and Jacques Robert, "Competition and Access in Electricity Markets: ECPR, Global Price Cap and Auctions," pp. 47-74 in Georges Zaccour (ed.), Deregulation of Electric Utilities, Kluwer Academic Pub., 1998.

${ }^{29}$ For a discussion of the real options approach to evaluating investment decisions, see Marcel Boyer, Peter Christofferson, Pierre Lasserre, and Andrey Pavlov, "Value Creation, Risk Management and Real Options," Icfaian Journal Of Management Research, October 2004 (CIRANO 2003RB-02).
} 
is particularly important in a highly volatile environment such as the telecommunications industry environment. ${ }^{30}$

This leads to two important observations. First, in reviewing pricing rules for inter-access to networks, the regulators must consider not only the development of competing networks on alternative technological platforms but also in each case the implicit costs of the real options exercised in developing the network infrastructures. Second, in reviewing the rules of competition between networks, the regulators should make explicit and transparent the procompetition special treatment that it wish to grant to some competitors rather than directly impose price and technology controls on others.

\subsection{The regulator's role as manager of the level playing competitive conditions and the proper control of predatory pricing through full cost sharing.}

In a standard natural monopoly industry, profits are likely to rise rapidly when the market expands since revenues then increase linearly or proportionately with the number of subscribers while costs increase typically very slowly due to the presence of economies of scale, economies of scope and network economies. The increase in profits means an increased rate of return on capital, exceeding over time by a significant margin the opportunity cost of capital of the firm. In any normal industry, this increased profitability would favour the entry of additional firms into the industry, but not necessarily in a natural monopoly industry. In this latter type of industry, the potential entrants understand that what is important and crucial for them is not the price they observe or the profits the incumbent firm is presently enjoying but rather the price and profits that they will be experiencing if and when they enter the market and compete with the incumbent firm.

It is post-entry goods and services prices that preoccupy the potential entrants, not actual preentry prices. In particular, if it is understood that regulators are going to control pre-entry prices

\footnotetext{
${ }^{30}$ For a discussion of real options and access pricing in network industries, see Jerry Hausman and Stewart Myers, "Regulating the United States Railroads: The Effects of Sunk Costs and Asymmetric Risk," Journal of Regulatory Economics 22(3), 287-310, 2002. See also Marcel Boyer, Eric Gravel, and Pierre Lasserre, "Real Options And Network Access Pricing Under Uncertainty”, mimeo, CIRANO 2005.
} 
at a relatively low level but that they will let prices be freely determined once new competitors have entered the market, then observed pre-entry prices will have no effect on the decision to enter or not. Potential entrants will evaluate what competitive post-entry prices are likely to be and then decide if those prices justify entry or not.

However, if pre-entry prices are determined and chosen by the incumbent, they may be a signal of the incumbent's cost - high prices signalling the presence of a relatively inefficient, high cost incumbent and low prices signalling the presence of a relatively efficient, low cost incumbent - and used as such by a potential entrant to decide if it can compete against the incumbent. But if the entrant uses the observed prices chosen by the incumbent in such a way, one must expect that the incumbent will choose its prices differently. Such strategic pricing is likely to result in social welfare losses.

If the regulated pre-entry prices in the local wireline services market are fixed at a relatively low level in order to prevent monopoly pricing, it may give the wireline incumbent a hedge insofar as these regulated prices prevent the emergence of alternative bundles of services offered over competing technologies. If those technologies cannot profitably compete with the low prices set by the regulator for the local wireline services market, then consumers will eventually suffer from the reduced technological advances and the reduced variety in products and services. A short-term benefit from lower local wireline prices is obtained at the expense of a long-term cost in terms of reduced choices, reduced innovation efforts, and reduced competitive pressures.

If the regulated pre-entry prices in the local wireline services market are fixed at a relatively high level in order to prevent predatory pricing and favour competition (through imposing floor prices on the ILEC without regulating in any way the CLECs' pricing; forbidding winback actions by the ILEC for a certain period; and other similar policies), it may give the competitors (the CLECs) a hedge insofar as the regulated prices prevent the incumbent to compete 
efficiently. Such pricing regulation is likely to prevent the emergence of a more efficient portfolio of goods and services offered to customers, at least in the short run. ${ }^{31}$

We need a different, more efficient approach to controlling monopoly pricing and predatory pricing while avoiding the subsidization of inefficient entrants, that is, a more efficient approach to developing a level playing field in short run competition while at the same time keeping a high intensity of incentives for long run competition. This more efficient approach rests on unregulated pricing of telecommunication services subject to general pricing policies that the regulator can impose and enforce on all players, ILECs and CLECs.

The current dominant approach to the prevention of monopoly pricing and predatory pricing in networks rests on the notions of marginal, incremental or avoidable (MIA) cost. Although these three concepts of cost are not exactly the same, they share similar foundations. The marginal cost is the additional cost a firm must incur to increase its production of a given service by a small amount; the incremental cost refers to the same concept for more important increases; the avoidable cost refers to the reduction in cost a firm would experience if it were to drop the production of a particular good or service from its current portfolio of products and services (the avoidable cost includes therefore the fixed cost specific to that product or service).

A firm is considered capable of exercising market power if its price for a particular good or service could profitably be set significantly above its MIA cost, including its MIA cost of capital, for a significant period of time. It could be considered guilty of predatory pricing if its price for a particular good or service is below its MIA cost for that good or service, including again its MIA cost of capital. Unfortunately, the use of the concept of MIA cost is a source of major problems and conflicts. The problems and conflicts stems from the fact that the MIA cost of a particular good or service is a concept suffering from five major shortcomings when economies of scale and scope as well as network economies are present, as in

31 What is wrong with lower prices? Low prices, or more generally loss leaders, may be detrimental for competition if they are intended to harm competitors. If they are not, for instance if a telecommunications provider announces a sale of telephones, at prices below costs, in order to reduce costly inventories of slow moving goods, then such low prices would be considered fair rather than predatory. In boxing, there is a difference between fighting and trying to beat the opponent by throwing hard punches to put him unconscious (legal, fair) and doing it by biting the opponent's ear (illegal, unfair). In tennis, one is allowed to smash the ball as hard as he can but not to aim at the opponent's head. Similarly with fair low prices and predatory low prices. 
telecommunications: it is non additive, order-dependent, unstable, manipulable, and horizondependent.

Non additivity refers to the fact that if all goods and services produced by a given firm operating under increasing returns to scale were allocated costs equal to their respective MIA cost, the sum of those allocated costs would be less than the total cost of producing the set of goods and services considered. It is a major problem insofar as one wants to determine the true contribution of a particular good or service to the total cost of the firm in order to use such a cost contribution for determining the proper non-predatory price level. In the particular case of telecommunications, the existence of significant economies of scale, economies of scope and network economies implies that the MIA cost of a good or service will typically underestimate the true contribution of the good or service to the total cost of the firm. Hence, this notion of MIA cost can hardly be defended as non-predatory.

Order-dependency is an even more problematic shortcoming of the notion of MIA cost. It refers to the fact that if one places all goods and services in some order (for instance in historical or date of introduction order, or in market size order) and then computes the MIA cost of adding the good or service to the subset of goods and services coming before it in the order considered, then the MIA cost of the good or service depends on that subset, that is, on the order of the good or service in the set. Given that the order is quite arbitrary, the MIA cost of the good or service is at best ill defined making it barely suitable for regulatory purposes.

Instability is a more subtle shortcoming but nevertheless an important one. It says that allocating costs on the basis of the MIA cost of the different goods and services could lead to a virtual disintegration of the firm in the following sense. Consider a subset of goods and services; it is possible that the total production cost of this subset alone be smaller than the total allocated cost to this subset. Hence, it would seem better for this subset of goods and services to be produced independently (as a separate entity) of the other goods and services. In that sense, the MIA cost procedure cannot guarantee the stability of the "coalition" of all the goods and services offered by a given firm. 
Manipulability refers to the fact that the list of cost elements to be included in the computation of the MIA cost is in practice subject to manipulation and debates between advocates. This is a major source of conflict even when all parties accept the concept itself. The recent case before the Canadian Competition tribunal involving Air Canada and the Commissioner of the Competition Bureau is illustrative of such conflicts. ${ }^{32}$

Horizon-dependence refers to the fact that the notion of MIA cost depends on the horizon over which the firm is reallocating its resources to optimally accommodate the increase in production or the abandonment of a good or service. The shorter the horizon considered, the lower the MIA cost as little can be saved in the short run by reducing production. And the difference in MIA costs over different horizons can be substantial. Since the proper horizon to consider is a matter of judgement, the MIA-based predatory pricing test is likely to be in good part arbitrary. Hence the difficulty of using this cost concept in regulatory cases.

Clearly, a proper notion of cost allocation for the purpose of verifying if a firm's pricing behaviour violates the non-predatory pricing rules must satisfy the requirements of additivity, order-independence, stability, non-manipulability, and horizon-independence. One such cost allocation procedure is the Shapley-Shubik (SS) cost allocation rule. ${ }^{33}$ In a nutshell, this rule corresponds to the average MIA cost over all possible production orderings of the goods and services offered by a firm. Rather than taking simply the usual MIA cost, the SS procedure takes the average MIA cost over all orderings thereby making it immune to the shortcomings of the cost allocation rule based on the MIA cost.

Moreover, the SS cost allocation rule has two other important properties, which prove very helpful in practice. First, it is such that the cost shares are invariant to the decomposition of total cost between specific and common or joint costs. This property is important because the decomposition of the total costs between joint costs (to be shared) and specific costs (to be

\footnotetext{
${ }^{32}$ See Competition Tribunal, Commissioner of Competition v. Air Canada, 2003 Comp. Trib. 13 Reasons and Findings (File number CT 2001002, Registry Document no 145a).

${ }^{33}$ See Marcel Boyer, Michel Moreaux and Michel Truchon, "Partage des coûts et tarification des infrastructures Enjeux, problématique et pertinence", CIRANO 2002RB-03 (novembre 2002, 41 pages), "Partage des coûts et tarification des infrastructures - Les méthodes de partage de coûts: un survol", CIRANO 2002RP-18 (November 2002, 53 pages), and "Partage des coûts et tarification des infrastructures - Les méthodes de partage de coûts: propriétés", CIRANO 2002RP-19 (November 2002, 73 pages).
} 
borne by the specific good and service causing them) is very often a source of conflict. The fact that the decomposition is irrelevant is therefore a property that is most welcome. Second, the SS cost sharing rule satisfies demand monotonicity, which means first that the cost allocation of a good or service increases if the demand (production) of that good or service increases while the production of others remain constant, and second that under economies of scale the cost share of a good or service decreases if the production of another good or service increases while its own production remains constant. Again, this property is conducive to an agreement between different stakeholders. More generally, the cost allocations obtained from applying the SS procedure can be shown to be an almost costless surrogate for the cost allocation that would be obtained through lengthy and costly bargaining "between the different goods and services" (or their demanders/consumers) as to the proper allocation of common costs. ${ }^{34}$

The regulator would consider a firm guilty of predatory pricing if the firm is found pricing one of its products or services below the per unit cost allocation associated to that product or service in the total cost of the firm. Hence, the per unit cost shares become the price floors under which a firm would not be allowed to price any of its goods and services. Those price floors are determined by the "real" cost function of the firm itself and not by some argument regarding the necessity to grant some advantage to competitors. If a firm is indeed more efficient than another, it should be able to achieve per unit cost for its goods and services that are generally lower than those of its competitors. In that sense, the SS cost allocation rule is a procompetitive minimum pricing rule, protecting all firms, incumbents and competitors, against predatory pricing, and creating adequate incentives for all firms to reduce the cost of their respective goods and services, thereby developing a level playing field with similar competition rules for everyone. In the presence of economies of scale, economies of scope and network economies, the SS cost allocation rule delivers the proper pricing benchmark compatible with the belief that competitive pressures constitute the most important dynamic driver behind social and economic static and dynamic efficiency.

\footnotetext{
${ }^{34}$ Other properties are discussed in the references mentioned above (footnote 29).
} 
The experience gathered over time in diverse applications of the SS cost allocation rule ${ }^{35}$ makes it a good candidate for the basic pricing rule. This does not mean that the application of the procedure is (always) easy and straightforward but none of the alternative procedures, and certainly not the one presently used, is easy and straightforward either.

Applying this test in predatory pricing cases must be done efficiently, that is, by minimizing the implementation costs. At the present time, the MIA test is applied repeatedly in predatory pricing and antitrust cases with plaintiffs and defendants producing evidence before the Competition Bureau, Competition Tribunal, or Antitrust Authorities and pleading their respective statements of case. Lawyers, accountants, engineers, and economists are called as expert witnesses to help the authorities decide on the different cases. The same could be done with the SS test. This test requires a bit more data, which will be provided by the firms themselves as it is the case in most applications of the MIA. But even if it were somewhat more costly than the MIA test, the SS test has many advantages: it is more coherent and transparent, more easily understood, and has characteristics that are crucial in designing a level playing field in telecommunications, namely additivity, order-independence, stability, non-manipulability, and horizon-independence. Firms, regulators and expert witnesses should be able to move rapidly down the learning curve. The SS cost allocation rule appears therefore as a powerful engine of competition and a properly intense incentive mechanism to foster innovation, both technological and organization, and creative destruction the benefit of all Canadians.

How then can the government (or the CRTC) adopt a pro-active strategy to favour the emergence of competition. Such a strategy could result from the fact or belief that the incumbent has obtained or developed an "unfair" advantage. The answer is simple: by subsidizing directly the entrant to compensate for the "unfair" competitive advantage of the incumbent. One way to do it would be to make a lump-sum or per unit transfer payment to the entrant. This may however induce entry by inefficient operators. An alternative could be to promise entrants a generous but deferred investment grant or tax credit to be paid $\mathrm{N}$ years after

\footnotetext{
${ }^{35}$ See H.P. Young, “Cost Allocation,” pp. 1191-1235 in Robert .J. Aumann and Sergiu Hart (Eds.), Handbook of Game Theory - Vol. II, North-Holland: Amsterdam, 1994; and Marcel Boyer, Michel Moreaux and Michel Truchon, "Partage des coûts et tarification des infrastructures - Enjeux, problématique et pertinence", CIRANO 2002RB-03 (novembre 2002, 41 pages) for discussions of some of those applications.
} 
entry conditional on the entrant's acquisition of a market share larger than $\mathrm{X} \%$. Only entrants with superior products or services, and/or superior technology, and/or better quality consumer service, or who believe that they can beat the incumbent one way or another, will enter the industry.

\section{CONCLUSION}

I argued in this report that the traditional market shares measure of competition is inadequate in the telecommunications industry because this industry has more the characteristics of an emerging industry than those of a mature industry. Different indicators have been discussed to reach the conclusion that the level of competition is relatively intense. I claimed that Canada needs a significant and urgent review and transformation of the policies and means of the telecommunications regulator (CRTC). The role of the regulator should be focused on three responsibilities:

- Acting as the trusted generator of information for the consumers on pricing structures and product characteristics, underlying the derived demand for telecommunications goods and services, namely connectivity, flexibility, safety, dependability, accessibility, capacity -- high speed and broadband --, and user-friendliness;

- Acting as the manager of the level playing field conditions to favour both static efficiency and dynamic efficiency and enacting indirect policies to control monopoly and predatory pricing, based on full cost sharing between goods and services offered by any given firm (as provided by the cooperative game theoretic SS cost allocation rule);

- Acting as the promoter of efficient investment programmes in network development and maintenance to guarantee the integrity of the global telecommunications network in Canada and designing access pricing rules incorporating all network access costs (including the real options costs embedded in completed networks).

Those redesigned responsibilities of the regulator are in fact the end point of the sequence of regulatory reforms that have been implemented over the last 15 or 20 years. The telecommunications industry regulator would become a truly pro-competitive watchdog, an integral part of the implementation of the Canadian Competition policy. 
Although the information gathering, the institutional reforms and the change of minds and attitudes required to implement a true pro-competitive regulatory framework for telecommunications in Canada, in particular for the local access markets, represent a sizable and significant undertaking, it is no more and probably much less demanding than the current regulatory framework.

Since the change in approach will take some time, it is urgent for the Canadian Authorities to launch a significant program of research, consultation and transformation, aimed at developing the necessary means and procedures to implement eventually a switch to the new procompetition rules proposed in this report. 